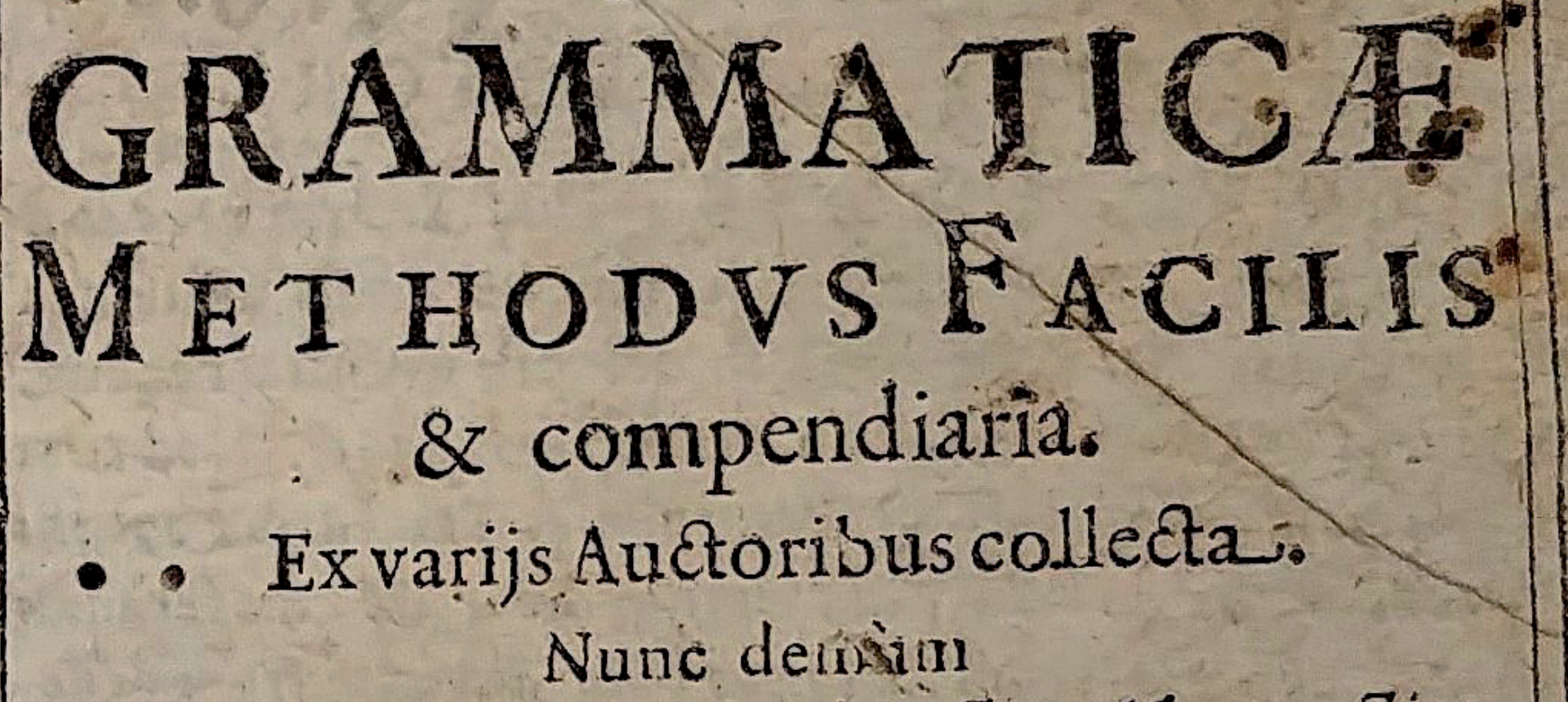

Ex Typographia Cefarÿ longè austior \& correctior $f a i t a$, at $g_{3} P$ glonico Idiomite illuffrata, in lecem Gublicamprodit.

SEBASTIANVS FABIANVS ACERNVS
in artem Grammaticam.

Sime fortè roges, quid fit fapientis Homeri,

Parce proueniens É inextirpabile Moly;

Cuipice nigrior est radix, fed lacte nowello

Flos est candidior, modicágs perutilis arii.

Nil aliud, quaim Grammatices elementa notavit,

Fabula diuini floris : nam caulis amarus

Nigre radicis, iuwenum fu/piria fignat,

Qui modo Grammatices in primo limine plor ant? Sedfos lacteus, in fummog cacumine ludens, Iucundos artis fruetus \& promic adumbrat. 
Sztuka Edycji 2/2018

ISSN 2084-7963 (print)

ISSN 2391-7903 (online)

s. $107-111$

\section{Nieznany wiersz Sebastiana Fabiana \\ Klonowica}

\author{
(opracowanie edytorskie Grażyna Łabęcka-Jóźwiakowska)
}

Sebastian Fabian Klonowic (Sebastianus Sulmircensis Acernus) zamieszkał w Lublinie w 1569 lub $1570 \mathrm{roku}^{1}$. Niemal natychmiast, bo w $1571 \mathrm{roku}^{2}$, rozpoczął działalność pisarską i wydawniczą o ukierunkowaniu dydaktycznym. Wśród licznych prac autora można bowiem wskazać co najmniej pięć służących głównie edukacji i wychowaniu dzieci: Formulae puerilium colloquiorum pro primis tyronibus, per Sebaldum Heyden ex comicorum campo hinc inde collectae, iam et denuo auctae, ac Polonico Germanicoque idiomate illustratae (bez miejsca i daty wydania oraz nazwiska drukarza) ${ }^{3}$, Philtron [...], quo in aestimabilis vis charitatis Christianae exprimitur (Cracoviae, in off. Andreae Petricovii, 1582), Catonis disticha moralia, castigatissima Polonicis versibus elucidata. Katonowe wiersze podwójne, dobrych obyczajów uczace prawie wedle potrzeby poprawione i rytmami polskiemi wyświetlone

${ }^{1}$ Maria Stankowa stwierdziła, że poeta przybył do Lublina już w 1568 roku; M. Stankowa, Sebastian Klonowic (Klonowicz), pisarz i rajca miasta Lublina, 1573-1602 (karta z dziejów ksiąg miejskich lubelskich), „Archeion” 1967, t. 46, s. 97. Halina Wiśniewska ustaliła na podstawie wpisów w księgach miejskich lubelskich (scil. zapis zeznania Klonowica, będącego świadkiem w procesie w 1598 roku), że autor do królewskiego miasta przeprowadził się w 1570 roku; H. Wiśniewska, Renesansowe życie i dzieło Sebastiana Fabiana Klonowica, Lublin 2006, s. 17. W styczniu 1598 roku (scil. Feria Secunda pridie Sanctorum Sebastiani et Fabiani Martyrum, 1598) „Spectabilis et Famatus Sebastianus Fabianus Acernus, civis et consul Lublinensis” zeznał, co następuje: „.... Barbara Boguczyna, niebożka, nigdy ani protestacyjej [sic!], ani pozwem tego to pana Konarzewskiego nie molestowała, ani się z prawem swojem, jeśliże takie miała, nie ozywała - i do tego dołożył - będąc tu, przy Lublinie, lat 28, tedy zawsze pamięta, iż tamten plac pustkami i odłogiem leżał i żaden się do niego nie ozywał”; Księga wójtowsko-ławnicza (za lata 2.01.1598-9.12.1600), Archiwum Państwowe w Lublinie, sygn. 35/22/0/2.1.1.1/20, k. 36v (transkrypcja z rękopisu - G. Ł.-J.). Jest jednak mało prawdopodobne, by Klonowic, mówiąc o dwudziestu ośmiu latach zamieszkiwania w Lublinie, rzeczywiście wskazywał na styczeń 1570 roku jako moment swojej przeprowadzki do miasta nad Bystrzycą. Można się jednak domyślać, że stało się to między latem 1569 roku a jesienią 1570 roku. Intuicję tę potwierdzają badania Mieczysława Mejora, który wpisy w księgach miejskich, wykonane przez młodego podówczas pisarza, odnalazł wśród dokumentów miejskich z 1569 roku; M. Mejor, Supplementum Acernianum. Nowe szczegóty do życiorysu i twórczości Sebastiana Fabiana Klonowica, „Ruch Literacki” 2004, z. 2, s. 151-152.

${ }^{2} \mathrm{Na}$ to wskazuje data wydania pierwszego z tych dzieł (vide niżej).

${ }^{3}$ Karol Estreicher podaje, że dziełko wydano w Krakowie, u Macieja Siebeneychera, w 1571 roku; K. Estreicher, Bibliografia polska, t. 28, z. 1-3, Kraków 1900, s. 180. 
(bez miejsca i daty wydania oraz nazwiska drukarza) ${ }^{4}$, Pamiętnik ksiąząt i królów polskich (bez miejsca i roku wydania oraz nazwiska drukarza) $)^{5}$ oraz Dworstwo obyczajów dziecińskich, dziatkom na polskie przetożone (Raków, druk. S. Sternacki, najwcześniejsza znana edycja 1602) ${ }^{6}$. Można przypuszczać, że wymienione prace były wykorzystywane w nauczaniu nie tylko w szkole kolegiackiej w Lublinie czy szkole w Zamościu, późniejszej sławnej Akademii, lecz także w innych placówkach.

Nie są to jednak jedyne ślady działalności dydaktycznej Klonowica. Zachował się także podręcznik do gramatyki Grammaticae methodus facilis et compendiaria, ex variis auctoribus collecta, nunc demum ex typographia Caesarii longe auctior et correctior facta atque Polonico idiomate illustrata, in lucem publicam prodit Sebastianus Fabianus Acernus $^{7}$ (Cracoviae, in off. Francisci Cezary [...], 1691) ${ }^{8}$. Estreicher widział jeszcze egzemplarz wcześniejszy, pod nieco innym tytułem, Methodus Facilis et Compendiosa, ex variis auctoribus collecta. Nunc demum auctior et correctior in usum puerilium studiorum conscripta, et Polonico idiomate illustrata (Cracoviae, in off. Stanislai Piotrkowczyk, 1671). Odnotował przy tym obecność dziesięciowersowego wiersza Acerna na karcie tytułowej. Druk ( $8^{\circ}$; ark. sygn. $\left.A_{2}-Q_{5}\right)$ znajdował się w bibliotece miejskiej we Wrocławiu'. Te z jej zbiorów, które ocalały, zasiliły po wojnie Bibliotekę Uniwersytetu Wrocławskiego ${ }^{10}$. W księgozbiorze uniwersyteckim nie ma już jednak żadnego egzemplarza interesującego nas podręcznika do gramatyki, co oznacza, że ten z 1671 roku zaginął. Biblioteka Zakładu Narodowego im. Ossolińskich dysponuje natomiast wydaniem Grammaticae methodus facilis et compendiaria [...] z $1717 \mathrm{roku}^{11}$. Najstarszy poświadczony druk, pozbawiony karty tytułowej i karty A, znajduje się w Bibliotece Państwowej w Berlinie ${ }^{12}$. Wytłoczono go w 1633 roku w oficynie Antoniego Wosińskiego w Krakowie ( $8^{\circ}$; ark. sygn. $\mathrm{A}_{2}-\left[\mathrm{P}_{5}\right]^{13}$.

Zachowane wydania wskazują, że podręcznik cieszył się popularnością jeszcze w XVII i na początku XVIII wieku. Brak edycji wcześniejszych pozwala sądzić, że wszystkie egzemplarze zostały „zaczytane”. Jego powstanie Halina Wiśniewska połączyła z pracą Acerna w szkole w Zamościu ${ }^{14}$ przypadającą na lata 1589-1591. Nie jest

\footnotetext{
S. 99.

${ }^{5}$ W literaturze przyjmuje się, że prace te wydano ok. 1590 roku oraz że jest to druga edycja przekładu Vitae Regum Polonorum Janicjusza pióra Acerna. Autorka przygotowuje artykuł na temat atrybucji tzw. wydania pierwszego zatytułowanego: Królów i książąt polskich, począwszy od Lecha aż do dzisiejszego potomka Jagiełtowego, Najaśniejszej Anny, królowej Jej Mci polskiej, i małżonka J.K.M., Najaśniejszego Stefana Pierwszego, a z łaski Bożej króla polskiego, wielkiego ksiazżęcia litewskiego etc., a wojewody siedmiogrodzkiego etc. króciuchne porządu zawarcie i opis nowo uczyniony roku 1576 (bez miejsca i daty wydania oraz nazwiska drukarza).

${ }^{6}$ Zakład Starych Druków Ossolineum, sygn. XVII 5894. W zbiorach Biblioteki Jagiellońskiej znajduje się także fragment innego wydania, niewiadomej oficyny (sygn. 585349 I). Problem różnych edycji tego dzieła omawia A. Litwornia, S. F. Klonowicza „Dworstwo obyczajów dziecińskich dziatkom na polskie przełożone" z Erazma i Lorichiusa, w: Per Jan Ślaski, magiaristi, polonisti, slavisti, italiani, festeggiano il Suo settantesimo compleanno con scritti, raccolti e curati da: A. Ceccherelli, D. Gheno, A. Litwornia, M. Piacentini, A. M. Raffo, Padova 2005, s. 255-265.

${ }^{7}$ Przekład G. Ł.-J.: Łatwa metoda i szybsze sposoby uczenia się gramatyki, zebrane z różnych autorów, teraz dopiero z typografii Cezarego uczynione daleko bogatszymi i poprawniejszymi oraz zobrazowane wyrażeniami polskimi, wystawił na widok publiczny Sebastian Fabian Klonowic.

${ }^{8}$ Egzemplarz Biblioteki Wyższego Seminarium Duchownego w Lublinie, sygn. XVII 5473, vide załączona fotografia.

${ }^{9}$ K. Estreicher, Bibliografia polska, t. 17, Kraków 1899, s. 325

${ }^{10}$ Podziękowania za te wiadomości należą się dr Agnieszce Franczyk-Cegle z Zakładu Starych Druków Ossolineum.

${ }^{11}$ Grammaticae methodus facilis et compendiaria, ex variis auctoribus collecta, nunc demum ex typographia Caesarii longe auctior et correctior facta atque Polonico idiomate illustrata, in lucem publicam prodit Sebastianus Fabianus Acernus, Cracoviae, in off. Francisci Cezary [...], 1717, sygn. XVIII-434.

${ }^{12}$ Za tę informację autorka artykułu dziękuje prof. Mieczysławowi Mejorowi.

${ }^{13}$ Staatsbibliothek zu Berlin, sygn. W 1518.

${ }^{14}$ H. Wiśniewska, Sebastian Fabian Klonowic. Urzędnik i poeta królewskiego miasta Lublina (materiały źródłowe: 1570-1603), Lublin 2010, s. 111.
}

${ }^{4}$ Według znakomitego bibliografa drukował Sebastian Sternacki w 1588 roku; idem, Bibliografia polska, t. 14, Kraków 1896,

Sztuka Edycji 2/2018 
to jednak oczywiste, zważywszy na to, że autor już wcześniej przygotowywał książkowe pomoce dydaktyczne do nauki języków czy historii.

Atrybucja książi budzi pewne wątpliwości. Jak sugeruje wspomniana już notatka Karola Estreichera, nazwisko poety jako autora Grammaticae methodus nie pojawiło się na karcie tytułowej wydania z 1671 roku. Dopiero później, w 1691 roku, zostało wplecione do części tytułowej w ten sposób, że jednocześnie odnosi się do całej książki i umieszczonego niżej łacińskiego wiersza ${ }^{15}$. Wolumin, choć zdefektowany, zachował się w dobrym stanie ${ }^{16}$. Został wydany w formacie bibliograficznym $8^{\circ}$ (octavo; wymiary $16 \times 9,5 \mathrm{~cm})$ i oprawiony w kartę pergaminową średniowiecznego łacińskiego rękopi$\mathrm{su}^{17}$. Pochodzi z biblioteki lubelskich kapucynów, na co wskazuje czarny, okrągły znak na grzbiecie tomu (duża litera „W” w ozdobnym okrągłym obramowaniu) ${ }^{18}$. Tekst jest wyraźny i czytelny, nie wymaga rekonstrukcji.

Liczący dziesięć wersów utwór, choć wspominany już przez badaczy ${ }^{19}$, nie doczekał się do tej pory publikacji. Przyjęto następujące zasady transkrypcji ${ }^{20}$ : uwzględniono zasady pisowni postulowane przez Stownik tacińsko-polski pod redakcją Mariana Plezi ${ }^{21}$, tj. wprowadzono rozróżnienie $u$ niespółgłoskowego i spółgłoskowego $(u / v)$, uporządkowano pisownię wyrazów z dyftongami (ae i oe); literę $j$ zastąpiono przez $i$, zapis słowa inextirpabile doprowadzono do inexstirpabile (to jedyna tego rodzaju ingerencja w tekst wiersza); zastosowano współcześnie obowiązującą zasadę zapisu majuskułą i zmodernizowano interpunkcję. Dla wygody czytelnika łaciński wiersz przełożono na język polski. Zawartość wersów tłumaczenia odpowiada zawartości wersów tekstu łacińskiego.

\section{Sebastianus Fabianus Acernus \\ In artem Grammaticam}

Si me forte roges, quid sit sapientis Homeri

Parce proveniens et inexstirpabile moly,

Cui pice nigrior est radix, sed lacte novello

Flos est candidior modicaeque perutilis arti,

5 Nil aliud quam grammatices elementa notavit

Fabula divini floris, nam caulis amarus

Nigrae radicis iuvenum suspiria signat,

Qui modo grammatices in primo limine plorant,

Sed flos lacteus, in summoque cacumine ludens,

10 Iucundos artis fructus et praemia adumbrat.

${ }^{15}$ Warto zaznaczyć, że na karcie tytułowej nad tytułem podręcznika znajduje się łaciński skrót N.N.C. Jak się zdaje, nie jest szerzej stosowany. Nie odnotowuje go także zbiór Sigla latina in libris impressis occurentia. Cum siglorum graecorum appendice. Skróty łacińskie w książkach drukowanych z dodatkiem skrótów greckich, oprac. M. Winiarczyk, Wrocław 1995. Możliwe jednak, że N.N.C. oznacza po prostu Nominis nescio cuius (nieznanego nazwiska), co wykluczyłoby Sebastiana Klonowica jako autora podręcznika.

${ }^{16}$ Brak kart A i A (wyrwane); wyciete po dwie karty (w każdej parze jedna była zapisana greckimi literami, co widać na resztkach papieru) spomiędzy składek A i B oraz P i Q, bez szkody dla tekstu. Książka nie nosi śladów użytkowania, są jednak plamy i przebarwienia będące wynikiem złych warunków przechowywania.

${ }^{17}$ Stan zachowania karty pergaminowej w oprawie przedstawia się nie najlepiej - mocno nadjedzona przez korniki, brzegi obszarpane, osypuje się podczas czytania. Wymaga konserwacji.

${ }^{18}$ Fundacja kościoła i klasztoru Kapucynów została zatwierdzona 24 czerwca 1723 roku. Nie wiadomo, ską podręcznik do gramatyki trafił do zakonników. Między wydaniem książki a zatwierdzeniem fundacji upłynęły wszak trzydzieści dwa lata.

${ }^{19}$ Między innymi w pracach Haliny Wiśniewskiej i Mieczysława Mejora.

${ }^{20}$ Zasady te zostały także zastosowane $\mathrm{w}$ transkrypcii tytułu podrecznika.

${ }^{21}$ Stownik tacińsko-polski, pod red. M. Plezi, Warszawa 2007, s. XXXIV-XXXIX. 
Sebastian Fabian Klonowic

Na gramatyke

Jeślibyś mnie zapytał, czym było mądrego Homera

rzadko wschodzące i niemożliwe do wyrwania moly,

które ma czarniejszy niż smoła korzeń, lecz od świeżego mleka

bielszy kwiat, i jest bardzo pożyteczny dla skromnej sztuki,

Nic innego nie oznacza jak tylko zasady gramatyki

bajka o boskim kwiecie: gorzka bowiem łodyga

czarnego korzenia oznacza westchnienia młodzieńców,

którzy teraz płaczą u samego progu nauki gramatyki,

lecz mlecznobiały kwiat, tańczący na samym szczycie,

przyjemne sztuki owoce i nagrody wyraża.

Szczegółowa analiza i interpretacja łacińskiego utworu przekracza ramy tego szkicu. Warto jednak wspomnieć, że autor zaczerpnął temat wiersza z dziesiątej księgi Odysei:

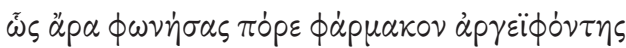

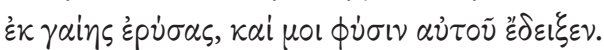

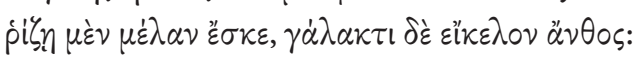

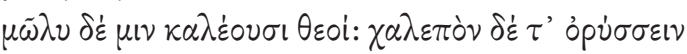

$\dot{\alpha} \nu \delta \rho \dot{\alpha} \sigma l \gamma \varepsilon \theta \nu \eta \tau \sigma i \tilde{\sigma l}, \theta \varepsilon \circ \grave{~} \delta \dot{\varepsilon} \tau \varepsilon \pi \dot{\alpha} \nu \tau \alpha \delta \dot{\nu} \nu \alpha \nu \tau \alpha \iota^{22}$.

Autor zaczerpnął
temat wiersza
z dziesiątej
księgi Odysei

Tak rzekł Hermes i ziółko pokazał mi one

Z ziemi wyrwane, dziwną mocą obdarzone:

Korzonki miało czarne, kwiat białości mleka,

Moly zwie się u bogów. Dotąd nie ma człeka,

Który by je wykopał. Wszystko w mocy bożéj!?3

O obdarzonej tajemną mocą roślinie pisali także Owidiusz w Metamorfozach ${ }^{24}$ oraz Pliniusz Starszy w Historii naturalnej ${ }^{25}$.

${ }^{22}$ Hom. Od. 10, 302-306, Homeri Odyssea, ed. G. Dindorf, corr. C. Hentze, p. I, Lipsiae 1930, s. 160.

${ }^{23}$ Homer, Odyseja (wybór), tłum. L. Siemieński, wstęp Z. Abramowiczówna, oprac. J. Łanowski, Wrocław-Warszawa-Kraków 1975, s. 185-186, w. 309-313.

${ }^{24}$ OV. Met. 14, 291-292: „Pacifer huic dederat florem Cyllenius album: / moly vocant superi; nigra radice tenetur”; P. Ovidii Nasonis Metamorphoses, ed. W. S. Anderson, Lipsiae 1977, s. 338-339; łłum.: „Miłujący pokój Kyllenius [Hermes - G. Ł.-J.] dał mu biały kwiat, / zwany przez bogów moly, który wyrasta z czarnego korzenia"; Owidiusz, Metamorfozy, tłum. A. Kamieńska (ks. I-IX, 175) i S. Stabryła (ks. IX, 175-XV), oprac. S. Stabryła, Wrocław-Warszawa-Kraków 1995, s. 385.

${ }^{25}$ PLIN. Nat. 25, 8, 26-27: „Clarissima herbarum est Homero teste quam vocari a dis putat moly et inventionem eius Mercurio adsignat contraque summa veneficia demonstrationem. nasci eam hodie circa Pheneum et in Cyllene Arcadiae tradunt specie illa Homerica, radice rotunda nigraque, magnitudine cepae, folio scillae, effodi haut difficulter. Graeci auctores florem eius luteum pinxere, cum Homerus candidum scripserit. inveni e peritis herbarum medicis qui et in Italia nasci eam diceret, adferrique e Campania memini aliquot diebus effossam inter difficultates saxeas radicis XXX pedes longae ac ne sic quidem solidae, sed abruptae"; C. Plini Secundi Naturalis historiae libri XXXVII, rec. atque indic. instr. L. lanus, vol. III, lib. XXIII-XXXII, Lipsiae 1859, s. 72; tłum.: „Według świadectwa Homera najsławniejszą jest roślina, którą według jego mniemania Bogowie moly nazwali, której odkrycie on Merkuryjuszowi przyznaje i wskazuje ja za środek przeciw największym czarom. Powiadaja, że dziś rośnie około Feneuszu i w Cyllenie, w Arkadyi, w tym samym kształcie, w jakim ją Homer opisał; ma korzeń okrągły, czarny, wielkości cebuli, liście jak morska cebula; wykopuje się ją z trudnościa. Greccy pisarze malowali jej kwiat żółto, gdy tymczasem Homer opisuje go białym. Znalazłem jednego, biegłego w botanice lekarza, który mi powiadał, że moly rośnie w Italii i po kilku dniach przysłał mi roślinę, z trudnością z kamienistego gruntu wykopaną; korzeń jej wynosił 30 stóp długości, a i tak nie był jeszcze w całości wykopany, ale przerwany"; K. Pliniusza Starszego Historyi naturalnej ksiag XXXVII, t. 8, tłum. J. Łukaszewicz, Poznań 1845, s. 153 i 155; o moly wzmianki w Historii naturalnej jeszcze w kilku miejscach, m.in.: 21, 105 i 180 oraz 25, 79 i 127. 
Cały koncept nawiązuje do alegorycznej wykładni tekstu Homera, zgodnie z którą $\mathrm{z}$ trudu i cierpienia rozwija się duchowe wychowanie, paideia. Korzenie moly są czarne, ponieważ początki paidei są ciemne i niewykształcone, trudne. Kwiat zaś owego zioła jest biały jak mleko, bo paideia błyszczy i jest słodka ${ }^{26}$. Jako że podręcznik został przeznaczony dla młodzieży, można wskazać także interpretację uproszczoną, dziecinną - to, co ciemne i budzące lęk, to wyłącznie trudności, po pokonaniu których czeka nagroda w postaci pięknego, rzadkiego białego kwiatu (talentu czy też doskonałości). Takie odczytanie fragmentu z Homera zostaje odniesione do trudu poznawania gramatyki łacińskiej. Treść wiersza koresponduje zatem z tytułem całego podręcznika - Grammaticae methodus facilis et compendiaria - Eatwa metoda $i$ szybsze sposoby uczenia sie gramatyki.

Zestawienie łatwości, sugerowanej przez tytuł, i trudności, za którą jednak czeka nagroda, ma nieco żartobliwy wydźwięk. Być może autor w ten sposób chciał dodać otuchy nieszczęśnikom rozpoczynającym naukę.

Key Words: Sebastian Fabian Klonowic, new Latin Rennaissance literature, Rennaissance literature, 16th century, Lublin, critical edition, grammar textbook, Latin grammar, didactic poetry, letter to a reader, education, Grammaticae methodus facilis, poem translation, Homer, Ovid, Pliny the Elder, Odyssey, Metamorphoses

Abstract: The article is devoted to a previously unknown poem entitled In artem Grammaticam (To grammar) by Sebastian Fabian Klonowic, a 16th century poet from Lublin. The composition survived in a grammar textbook from 1691, entitled Grammaticae methodus facilis et compendiaria $[. .$.$] . The work consists of two parts. In the first one, didactic aspects of Klonowic's work has$ been discussed (including his interest in matters related to youth education), the history of all known editions of Grammaticae methodus facilis textbook, the problem of lack of editions from before 1633. Another issue discussed is the attribution of forgotten Latin grammar. The second, major part of the text is an edition of the poem, which consists of its transcript (according to the provided rules of transcription), a translation and a short commentary, which, for instance, identifies ancient sources. 